\title{
La hermenéutica palabra-vida, hermenéutica de los pobres
}

\section{Alberto ParTa, S.J. Facultad de Teologia, \\ Pontificia Universidad Javeriana, Bogotá, Colombia.}

\section{El proyecto palabra-vida}

Una característica inconfundible de las comunidades cristianas populares o comunidades eclesiales de base ha sido su esfuerzo por una lectura racional y una reflexión creyente del texto de la vida y de la historia, de la situación, de la institución, del sistema, de la marginalidad, del subdesarrollo y de sus causas. Esta práctica se denomina, generalmente, análisis de la realidad. $Y$ tiene por finalidad auscultar la locución de Dios en los acontecimientos de la historia y poder discernir en ellos la presencia del misterio de iniquidad, como fuerza de muerte contraria al plan o proyecto salvador y liberador del Señor de la vida.

Esa práctica cristiana, propia de la base, está siendo una verdadera ascesis para buscar y hallar la voluntad de Dios, ya no sólo en los reductos estrechos de una conciencia religiosa ajena a su entorno, sino en la historia y en la situación donde acontecen las señales de Dios, que se han de interpretar a través de su Palabra. ${ }^{1}$ Porque las situaciones históricas son señal y realización del plan o proyecto salvador de Dios, y son también lugar en el cual se agazapan el mal espíritu, los ídolos contrarios al único señorío de Dios, y las fuerzas de la muerte que imposibilitan la vida humana y la existencia cristiana.

Además, la fuerza del Espíritu está rescatando la Palabra revelada del escritorio de los cultores de la exégesis fina y de los especialistas en semántica antigua e historia de las formas y de las 
tradiciones. En las comunidades, la base tiene en sus manos sudorosas y callosas la Escritura cristiana. De sus voces cansadas sale la lectura y el comentario situado (desde la situación) y situacional (referido a la situación) de la Biblia. Ella ilumina los problemas e inspira la vida y el caminar de la comunidad. Entonces se inicia en el seno mismo de las comunidades una producción teológica de base, que es reflexión comunitaria de su realidad, a la luz de su fe en Jesucristo, y a través de la mediación de las Escrituras cristianas. "Con un ojo en la realidad y con el otro en la Biblia," acostumbran a decir con su sabiduría popular. Así nace, en la base, el proyecto PalabraVida.

Tal práctica está devolviendo a la Palabra, testificada históricamente en la Escritura, su índole de Palabra viva para destinatarios concretos, que desde su postración no pueden tener como único interés el informarse de lo que "en aquel tiempo dijo el Señor a sus discípulos." Por lo cual, las características hermenéuticas de este modo de lectura, la hacen cualitativamente diferente de las sabidas y consabidas interpretaciones de la Escritura, desde ópticas e intereses no propiamente de abajo y menos de base, sin interés práctico en el camino humano y cristiano de la liberación de los pobres.

El mismo Cardenal Ratzinger en su "informe sobre la fe," apoyaba, sin pretenderlo, este modo de lectura bíblica popular, cuando afirmaba con razón:

Por obra de la investigación histórico-crítica, la Escritura ha llegado a ser un libro abierto, pero también un libro cerrado. Un libro abierto: gracias al trabajo de la exégesis, percibimos la palabra de la Biblia de un modo nuevo, en su originalidad histórica, en la variedad de una historia que evoluciona y crece, grávida de aquellas tensiones y de aquellos contrastes que constituyen, al mismo tiempo, su insospechada riqueza. Pero, de esa manera, la Escritura se ha convertido también en un libro cerrado: se ha transformado en objeto de los expertos; los laicos, incluso los especialistas en teología, que no sean exegetas, ya no pueden arriesgarse a hablar de ella. Casi parece sustraerse a la lectura y reflexión del creyente, puesto que lo que de ellos resultase sería tachado, sin más, como "cosa de diletantes." La ciencia de los especialistas levanta una valla en torno al jardín de la Escritura, que se ha hecho asI inaccesible a los no expertos.

Todo católico debe tener el valor de creer que su fe (en comunión con la fe de la Iglesia) superó todo "nuevo magisterio" de los expertos, de los intelectuales. Las hipótesis de estos investigadores 
pueden ser útiles para conocer la génesis de los libros de la Escritura, pero es un prejuicio de raigambre evolucionista pensar que sólo se comprende el texto estudiando como se ha desarrollado y creado. La regla de fe, hoy como ayer, no se halla constituida por los descubrimientos (verdaderos o meramente hipotéticos) sobre las fuentes y sobre los estratos brblicos, sino por la Biblia tal como es, tal como se ha lefdo en la Iglesia, desde los padres hasta el día de hoy. Es la fidelidad a esta lectura de la Biblia la que nos ha dado a los santos, que han sido con frecuencia personas de escasa cultura; en cualquier caso, ajenos siempre a las complejidades exegéticas. $Y$, sin embargo, han sido ellos los que mejor la han comprendido. ${ }^{2}$

La vida religiosa latinoamericana, tan profundamente ligada hoy a las bases populares y a sus luchas de liberación, no podia menos de aprender y practicar este modo de lectura (propio de los pobres) de la Biblia. A la luz de la realida histórica y de la realidad histórica a la luz de la Biblia. Nacia asi, dinamizado por la Confederación Latinoamericana de Religiosos (CLAR), el proyecto Palabra-Vida para la reflexión orante de los religiosos latinoamericanos en el quinquenio 1988 a 1993, y que se articula sobre los tres pilares fundamentales de la realidad latinoamericana, comunidad de los pobres de Jesucristo y texto de la Escritura Santa.

Lo demás ya se sabe: la descalificación inicial del proyecto por parte de las directivas del CELAM; por la actual directiva de la Conferencia Episcopal Colombiana; por las congregaciones romanas para religiosos y para la doctrina de la fe; la exacerbación de las tensiones entre obispos y religiosos en el continente; los presagios de silenciamiento del más notable maestro y propulsor de la lectura bíblica desde la realidad de los pobres; los nuevos obstáculos puestos a la liberación, pero también los nuevos horizontes que se abren en esta etapa conflictiva de la historia de salvación latinoamericana.

\section{La hermenéutica}

Es ingenuo pensar que la inicial descalificación del proyecto $\mathrm{Pa}$ labra-Vida sea un episodio reciente, sin conexión con otros episodios anteriores de la misma cadena. $O$ que lo que trate de invalidarse sea la materialidad del proyecto de lectura orante desde la realidad propuesta a los religiosos latinoamericanos por la CLAR, y no la forma general de hermenéutica, lectura o interpretación que va siendo corriente entre los pobres.

Y es porque América Latina ha aprendido a reflexionar su fe desde 
la vida; más aún, desde la anti-vida que caracteriza la realidad de este continente. Pero vivir y reflexionar la realidad a la luz de la fe tiene como supuesto ese método de unión ( $\sin$ mezcla y sin separación) entre una lectura racional y crítica de la realidad que nos oprime y que debe ser transformada (mediación socio-analítica) y una lectura creyente de esa realidad historica a la luz de las mediaciones historicas de nuestra fe (mediación hermenéutica).

Es entonces cuando, si no se insiste en señalar que la mediación socio-analítica de la reflexión latinoamericana está contaminada de sociologismo y de marxismo, se señala que su mediación hermenéutica, es decir, su recurso a la Escritura y a los demás elementos de la tradición, está mal hecha o es deficiente.

Más aún, ha llegado a señalarse que la hermenéutica latinoamericana es simplemente deudora de la hermenéutica racionalista de Bultmann y de su escuela. Así lo afirmó el Cardenal Ratzinger al describir lo que él piensa que son los "elementos fundamentales de la estructura cognoscitiva" de la teología latinoamericana:

Bultmann cobró también importancia para el desarrollo ulterior de una segunda palabra clave. El puso en primer plano el concepto ya antiguo de la hermenéutica, pero confiriéndole un nuevo dinamismo. En el término "hermenéutica" se expresa la idea de que para una comprensión real de los textos históricos, no basta una mera interpretación histórica, sino que toda interpretación histórica incluye algunas decisiones previas. La herrnenéutica tiene como misión "analizar" la Escritura en conexión con los datos que la historia, siempre cambiante, nos presenta: una "funsión de horizontes" del "entonces" y del "hoy" que, consiguientemente, nos plantea la pregunta ¿qué significa hoy aquel entonces? Bultmann contestó ya a esa pregunta sirviéndose de la filosofía de Heidegger, e interpretó la Biblia en clave existencialista. Esta pregunta ya no ofrece ningún interés; en este sentido, Bultmann ha quedado superado por la exégesis actual. Lo que sí permanece es el abismo entre la figura del Jesús de la tradición clásica y la idea que pueda y deba transferirnos esta figura actualmente, mediante una nueva hermenéutica."

Este "Informe" sobre la teología latinoamericana, que señala a Bultmann como padre de la hermenéutica que ella sigue, es el que sustancialmente se vuelve a encontrar en el numeral $X$, "Una nueva hermenéutica," de la "Instrucción sobre algunos aspectos de la teología de la liberación."

Pero el asunto de la hermenéutica no proviene de Bultmann. Es 
problema antiguo, como bien dice Ratzinger. Proviene de la estructura humana, del zoon hermeneutikón (animal interpretante) que es el hombre. Como tal y desde siempre, el asunto de la hermenéutica ha sido problema humano y, en cuanto tal, es también pertinente a la praxis y reflexión de fe latinaomericana, pero no sin las precisiones y en las perspectivas que ahora quisiéramos diseñar.

\section{La hermenéutica liberadora}

El historicismo dogmático y el dogmatismo textual (sobre los que volveremos después) significaron un anclarse en el pasado histórico. La que hoy denominamos hermenéutica liberadora es el esfuerzo por rescatar el presente, el aqui, el ahora, la esencial dimensión de historicidad del hombre.

\subsection{De la historia del pasado al presente}

En efecto, es la historia presente la que precisa ser interpretada para el encuentro con el ser y con la realidad, y no ya en el plano de lo puramente contemplativo y conceptual idealista, ni tampoco en el plano de lo puramente conformativo positivista, sino en el de una historia transformante y liberadora cuyo autor es el hombre de hoy, de aquí y de ahora.

No se oculta que todo tipo de hermenéutica liberadora se liga de alguna forma a la fenomenología de Husserl y a la analítica existencial de Heidegger, así como pasa de alguna manera a través de la interpretación existencial de la Escritura y de la teología de cuño bultmanniano.

La teología liberadora latinoamericana no reconoce paternidades directas. Pero no es menos cierto que la praxis y teología de hombres y mujeres latinoamericanos tiene que contar consciente o inconscientemente con ese como sistema ecológico total, a la vez social, humanístico y teológico que es contemporáneo a la teología liberadora. Entonces, en lo social, la praxis y la teología latinoamericana tienen derecho a orientarse por corrientes alternativas al sistema sociopolítico dominante. En lo humanístico, tienen derecho a decidirse por epistemologías desbloqueadoras de los habituales remanejos conceptuales. En lo teológico, América Latina se orienta por una hermenética que favorezca los procesos de liberación social, político-económica y cultural en que está empeñada.

La hermenéutica liberadora no persigue un imposible objetivismo histórico de tipo positivista, con independencia del sujeto histórico que realiza su historicidad propia hoy, aquí y ahora; y que, por 
consiguiente, hace, realiza y escribe su propia historia. Es que el encuentro con el ser y con la realidad no acaece simplemente por la acomodación a la historia del pasado y por la embelesada contemplación de la misma, sino por la actuación histórica libre y responsable en el presente. De ahi que la historia no se repita como en las mitologias del retorno y en las concepciones circulares del tiempo para las cuales pareciera que ya todo está dicho, todo pensado, todo resuelto. Por el contrario, la historia se individualiza y se particulariza por el hombre concreto que la realiza y que la vive. Es decir, que el hombre se comprende a sí mismo no simplemente comprendiendo la historia del pasado, sino al vivir su propia historia en una radical experiencia de ar mismo, de su mundo, de sus situaciones, circunstancias, cautividades y empeños por su liberación. 'Donde no se trata de que el hombre y las comunidades primero interpreten y después actúen, sino de que se autointerpreten como gestores y como realizadores de su propia historia e historicidad en la acción transformadora, original e inédita de sus propios compromisos y responsabilidades.

De ahí que nuestro quehacer no sea interpretar la historia pasada para ser nosotros mismos, sino ser nosotros mismos, ayudados posiblemente por la historia del pasado. Por eso, los dogmas históricos fijos e invariables del pasado no pueden pretender fundar por sí solos el ser, la conciencia y la acción, como tampoco fundar de una vez para siempre la política, la economía, el derecho o la religión. En particular, una hermenéutica liberadora pone en guardia contra la absolutización de datos y de dogmas no re-lativos a las circunstancias histórica que los originaron y que los explican, y por ello valora todo dato dentro de su correspondiente marco histórico sin pretensiones de experiencias o de expresiones totalizadoras, que pudieran ser negadoras o paralizantes de otras posibles experiencias y expresiones históricas.

Por lo que hace al cristianismo, las venerables tradiciones de su historia pasada y las respetabilidad de su dogmática habrán de valorarse sin prescindencia de sus correspondientes coordenadas de tiempo y espacio y sin pretensiones de recoger y de expresar de una vez por todas y para siempre todas las experiencias históricas posibles del decurso de la historia. Eso sin decir que el cristianismo no puede ser entendido positivistamente como transmisión de dogmas y de doctrinas para que se repitan, sino como impulsor de una experiencia fundante de fe que no le ahorra a nadie la aventura por su propia experiencia y por su propia interpretación actuante de la historia, del mundo de la salvación. En ese contexto puede situarse la intuición 
bultmanniana de no ser primaria y más importante la Textexegese (exégesis del texto), sino Lebensaktexegese (exégesis del acto de vida) en relación con posibles textos, doctrinas y dogmas del pasado.

\subsection{Del dogmatismo tertual a la hermenéutica tertual situada y situacional}

Si las nuevas hermenéuticas han sido reacción contra la vieja hermenéutica de cuño positivista, la nueva hermenéutica textual señala también una reacción contra el inveterado dogmatismo textual. Más aún, una hermenéutica liberadora postula necesariamente una nueva práctica en la hermenéutica textual, que no sirva para repetir con simpleza el pasado, sino que coadyuve a la interpretación transformadora del presente.

La hermenéutica puramente textual o exégesis antigua tuvo como preocupación preeminente desentrañar el significado filológico, semántico y gramatical de los textos, casi por completo de espaldas a las situaciones historicas desde las cuales se interpreta y se vive. De ahí las pretensiones de validez objetiva universal: el mismo valor y sentido de los textos para Europa, para Africa y para América Latina. Hubo quienes hicieron saber la rotunda imposibilidad de una hermenéutica textual de san Pablo o de san Lucas para América Latina.

Hoy, en cambio, va siendo corriente la conjunción necesaria entre hermenéutica textual y la historia real que se vive y que se hace. Ello da por resultado una lectura situada y situacional de los textos; de forma que ofrezcan sentido, es decir, correlación con las situaciones, ilusiones, angustias y necesidades de personas reales. Si esa cortelación no pudiera establecerse y no ya a un simple nivel extrinsecista y piadoso, sino hondamente teológico y científico, la hermenéutica textual no pasaría de ser una información arqueologica, filologica, semántica, gramatical.

La conjunción de texto y situación histórica real se hace sobre los siguientes principios.

El yo que inteprreta no es un ser abstracto, aséptico, que pueda prescindir de sí mismo en el momento de interpretar, para buscar un sentido textual "en sí." El yo que interpreta interroga a los textos desde su mismidad, es decir, desde su situnción y su historicidad.

El yo que interpreta es parte constitutiva de la interpretación misma. El intérprete es elemento interno de la interpretación. De ahí que cada intérprete deja la impronta de sí mismo en cada una de las 
interpretaciones que hace. $Y$ es porque el interpretar es percibirse $y$ autocomprenderse con relación al momento histórico, por una parte; y al texto interpretado, por otra. La recta hermenéutica trata de referir un texto al contexto actual de vida y de iluminar dinámicamente el texto con el contexto y el contexto con el texto.

Los textos del pasado no pudieron, ciertamente, prever las circunstancias históricas y las situaciones particulares de los intérpretes en el decurso de la historia subsiguiente. Pero, si el texto no es apto para establecer la analogia de proporcionalidad o la correlación cierta con las circunstancias particulares del intérprete situado, ello significaria que el texto no es hermenéuticamente renovable ni apto para transmitir mensaje alguno a la realidad actual, sino tan sólo datos del pasado remoto, con el único interés de saber cómo fueron las cosas in illo tempore.

Los textos del pasado, especialmente de la Escritura, adquieren sentido operativo cuando coadyuvan a percibir el presente de nuestra salvación y en cuanto ofrecen un puente de correlación con la historia de salvación que acontece hoy, aquí, ahora. Si el evangelio de Marcos - los textos de Pablo no pueden ser hermenéuticamente correlacionados con la problemática conflictual de América Latina, con sus ansias, esperanzas, logros y fracasos, significaria que la Escritura nada tiene que decir hoy al hombre situado, y que la Escritura ha llegado a ser artefacto de museo y pieza de archivo. Nadie puede dudar hoy de que la interpretación para una comprensión con sentido operativo acaece en el punto de convergencia entre la situación histórica del intérprete y el texto interpretado, no ciertamente desde un pre-juicio, pero sí desde una inevitable pre-comprensión.

Las relecturas del Evangelio, como lo advirtio Juan Pablo II en el discurso inaugural de Puebla I, 4, están expuestas a los riesgos de teorización, inadecuación, reducción e incluso manipulación por parte de quien lo interpreta desde una situación dada. Sin embargo, el Evangelio tiene que entrar en conjunción con las categorías antropológicas y sociales de cada época y de cada cultura, como lo enseñó Pablo VI en la Evangelii Nuntiandi, 63. La historia de la hermenéutica cristiana es y ha sido historia de las relecturas circunstanciales del Evangelio referido a la existencia histórica de intérpretes concretos. El excesivo temor de algunos por las relecturas desde la situación puede conducir a la parálisis de la interpretación cristiana que sea significativa y con sentido para la práctica del hombre de aquí y de ahora. Por lo demás, si el Evangelio ha sido y es interpretado, leído y releído desde Europa y desde oriente, no se ve la razón por la que no 
haya de ser lefdo y relefdo desde la peculiar situación de los pobres de América Latina, desde su opresión y praxis de liberación.

La misma Congregación para la doctrina de la fe, después de su drástica crítica a algunos aspectos de la teología de la liberación, en momento de mayor lucidez se expreso de esta manera:

Una reflexión teológica desarrollada a partir de una experiencia particular puede constituir un aporte muy positivo, ya que permite poner en evidencia algunos aspectos de la Palabra de Dios, cuya riqueza total no ha sido aún plenamente percibida. Pero para que esta reflexión sea verdaderamente una lectura de la Escritura, y no una proyección sobre la Palabra de Dios de un significado que no está contenido en ella, el téblogo ha de estar atento a interpretar la experiencia de la que él parte, a la luz de la experiencia de la Iglesia misma.?

\section{La hermenéutica de la dominación}

La actual práctica generalizada de acusar a comunidades, télogos, escritos, libros y conferencias pareciera llevar implícito el inaceptable principio de que todos somos culpables hasta que demostremos la inocencia. Entonces pareciera que son los acusados quienes deben justificar sus posiciones, legitimarlas y sostenerlas. Pero quien acusa o quien critica pareciera que gozara de legítima posesión de la verdad y que no tuviera que justificar, ni legitimar, ni sostener con argumentos convincentes las críticas y las acusaciones que formula.

¿Desde dónde, desde qué intereses, desde cuáles hermenéuticas se rechaza lo que hemos descrito como hermenética liberadora? No lo sabemos. No lo han dicho. No lo han explicitado.

Sabemos, sí, que existe una vieja hermenéutica (en uso todavia en los círculos decadentes) que no podemos sino tildar de positivista y opresora y que en líneas generales, podríamos caracterizar de la siguiente manera.

\subsection{El historicismo dogmático}

Las corrientes idealistas y racionalistas de toda época, pero especialmente del siglo XVIII, señalaron al concepto, a la idea, al producto de la deducción racional lógica como única vía de acceso del hombre a la realidad, al ser; y ello no sin las sobrecargas del individualismo y del subjetivismo de que han sido justamente reconvenidas. La sicología y la sociología del conocimiento no operaron jamás como elementos históricos determinantes del acceso del hombre a la realidad. 
Las corrientes histórico-positivistas de toda época, pero especialmente del siglo XIX, quisieron contrarrestar las pretensiones del racionalismo e idealismo por el señalamiento de una via alterna para el encuentro con el ser y la realidad: la historia de ayer vivida por el hombre de siempre. Camino garantizado para el acceso a la verdad no sería lo intelectual y simplemente racional y especulativo, sino el análisis de la historia del pasado que debería servir al hombre como norma del presente.

La historia fue entonces lugar de la verdad y del encuentro con la realidad. Analizar los procesos históricos, en forma análoga a los análisis efectuados por las ciencias empíricas, equivaldría a indagar por el proceso de la verdad y de la realidad. Más aún, nada demostrarfa ser verdadero hasta tanto no fuera experimentado en sus desarrollos históricos, en su génesis histórica, en sus condicionamientos y leyes históricas. De esta forma se desplazaba lo teórico del idealismo hacia lo empírico del historicismo. ${ }^{8}$ Los análisis de la historia del pasado serían el inequívoco soporte de las ciencias, no la deducción de principios abstractos.

Surgió entonces la escuela histórica del derecho en la que éste tiene su fundamento, no en la lógica, sino en la costumbre histórica del individuo o de la comunidad: a mayor y más antigua costumbre correspondería un más fundamentado derecho, así como la continuidad pragmática en la interpretación y aplicación de la norma constituiŕa la fuerza de la jurisprudencia, que vino a erigirse casi en primer principio de esa mecánica historicista y positivista propia del mundo de los cánones, de los códigos y de los tribunales.

De modo análogo apareció también la escuela histórica de economía política en la Alemania de 1800 como reacción contra los teóricos de la economía. Para la nueva escuela, la economía y sus leyes no se basarian en suposiciones abstractas y en imaginarias hipotesis sobre los previsibles comportamientos lógicos de la economía, sino en los datos reales y empíricos de la encuesta, en el análisis experimental de los desarrollos económicos del pasado. La economía se aprendería leyendo la historia, no calculando especulativamente el incierto futuro.

En teología, los datos históricos del pasado vinieron a ser poco menos que hipostatizaciones de la verdad. Los datos de la tradición, historicistamente entendida, parecieron excusar de toda ulterior reflexión y previsión. Hacer teologia llegó a ser casi sinónimo de conocer los datos históricos del pasado: la historia de Israel, la historia del paleocristianismo, la historia de los pobres, de los concilios y de los 
dogmas. Se configuraba así un concepto de tradición, entendida como comportamiento histórico constante, invariable y fijo, que vino a ser fuente primaria y casi única de la teología. Díganlo si no, los currículos repetitivos y formales de seminarios y facultades, parapetados en los métodos histórico-genéticos que en definitiva no son sino neo-dogmáticos. En el respaldo del pasado estaría salvaguardada la verdad del presente, así como la historia del pasado sería la razón explicativa del hoy cristiano.

La filosofía tendió a ser sustituida por el análisis positivista de la historia. Para un filósofo como Dilthey (1833-1911), quien pagó tributo al historicismo antimetafísico, el método de las ciencias no podría fundamentarse ni en la metafísica ni en el a priori, como lo hubieran pretendido los idealistas, sino en el análisis y en la descripción. La manera de hacer ciencia sería describiendo la realidad vivida y los hechos históricos en el conjunto de que forman parte. Para este mismo filósofo y las corrientes anejas, los modelos sociales, políticos, culturales, económicos, se repiten: todo dejaría su huella imborrable en la costumbre, en el arte, en los documentos del pasado y allí sería donde el hombre aferra la realidad y su propia condicion de ser histórico.

La historia vendría a ser, entonces, la repetición de unos mismos modelos, ya que el hombre de hoy es el mismo siempre. Más aún, la historia de hoy sería verdadera en cuento coincidiera con la historia de ayer; al coincidir las dos, la historia de ayer se haría contemporánea al hombre hoy. Así se entenderia que la historia es maestra de la vida. El hombre de hoy debería simplemente traducir la historia en conocimiento para saber comportarse convenientemente.

Por su exaltación desmedida de la historia del pasado como norma y dogma del comportamiento general del presente, el historicismo apunto hacia un determinismo histórico y un consiguiente fatalismo determinista. Avocó a una negación de la libertad del hombre, que no podria sino aceptar la historia, conocer la historia, conformarse a la historia, repetir la historia. Todo lo cual conduce en definitiva a un grave fenómeno de despersonalización de un hombre incapaz de atreverse a ser él mismo en su originalidad, autonomía, singularidad y creatividad, sino el repetidor de cuanto otros en el pasado dijeron e hicieron.

Si se quieren circunscribir los contornos más sobresalientes del historicismo habría que decir que persiguió un objetivismo histórico, contrastante con el subjetivismio racionalista e idealista. Su concepción del tiempo fue más circular-mítica que lineal-histórica, en cuanto 
que la historia pareciera repetirse delante de un hombre que permanece idéntico e inalterado en todas las épocas y circunstancias. Por eso, las mitologías del retorno parecen encontrar aquí puesto de honor: "nada hay nuevo bajo el sol," sino que gira el eterno carrusel de la historia y vuelven a representarse los mismos papeles en el teatro de la vida. La herencia, la tradición y la costumbre vendrian a ser dogmas para fundamentar las ciencias, especialmente de tipo humanístico; así como el análsis positivo sería el fundamento de las ciencias empíricas. De ahí que la investigación crítica en el terreno de las ciencias humanas hallaría su objeto, no en los sistemas de pensamiento, sino en los sistemas de vida del pasado que se constituyen en paradigmas de comportamiento en el presente.

\subsection{El dogmatismo textual}

El historicismo dogmático conduce inevitablemente al dogmatismo textual. Porque al pasado histórico se tendría acceso solamente por la interpretación de los documentos del pasado, de los textos, doctrinas y obras que narran las experiencias y los alcances del hombre de ayer. De ahí que los textos en los que se consignaron las experiencias y saberes vendrían a constituirse también ellos en dogmas y paradigmas a los cuales sería preciso atenerse. En tales perspectivas, la actividad hermenéutica queda delimitada a la labor exegética o interpretación textual. El texto es exaltado a la categoría de primer principio, válido por sí, originario de la verdad y del acceso a la realidad. No hace mucho tiempo pareció bastar con endilgar textos o auctoritates sobre las preguntas y perplejidades del hombre situado. Entonces la racionalidad exegética vino a ser clave de la inteligibilidad de la historia.

Asentado el principio historicista de que las experiencias históricas se objetivizan en vocablos y en formulaciones, a la interpretación textual no le queda otra función sino la de desentrañar lo de ayer para "revivirlo" y "actualizarlo" hoy, y establecer los dogmas históricos, que vengan a ser para la conducta humana lo que los primeros principios son para las ciencias. Por eso, el fruto de la interpretación textual sería obtener de los textos unos arquetipos de comportamiento (doctrinas), válidos hoy como ayer, dando por supuesta la identidad histórica del hombre. Entonces, la preocupación dominante de la racionalidad exegética es la de desentrañar por todo medio posible lo que el autor o autores quisieron expresar.

Así, el texto se divorcia de la vida presente y se aprisiona en su propio pasado, sin posibilidad alguna de ser renovado hermenéu- 
ticamente. Asi se bloquea el círculo hermenéutico que va del contexto histórico del intérprete al texto leído, y de éste nuevamente al contexto histórico del intérprete. Es decir, así se bloquea todo proyecto Palabra-Vida.

¿Será esta la perspectiva en la que se están formulando las críticas y las acusaciones, no tanto a la materialidad del proyecto de la CLAR, cuanto a la hermenéutica liberadora que practican en este continente todos los pobres de Jesucristo en su camino de liberación?

\section{Notag}

1. Concilio Vaticano II, Constitución Dei Verbum, n. 2

2. J. Ratzinger, Informe sobre la fe, Madrid, 1985, pp. 84-85.

3. Confederación Latinoamericana de Religiosoo, CLAR, Proyecto "PalabraVida," Bogotá, 1988.

4. J. Ratzinger, Informe sobre la fe, Madrid, 1985, pp. 198-199.

5. Congregación para la Doctrina de la Fe, Instruccion sobre algunos aspeclos de la teología de la liberación, Ciudad del Vaticano, 1984.

6. Cfr. H. G. Gadamer, "Fundamentos para una teorfa de la experiencia hermenéutics," Verdad y Método, Salamanca, 1977, pp. 39-460.

7. Congregacion para la Doctrina de la Fe, Instrucción sobre libertad cris. tiana y liberación, Ciudad del Vaticano, 1986, n. 70.

8. Es asgnificativo que casi todos los autores de la nueva hermenéutica incluyen un rechazo del positivismo e historicismo; cfr. R. Bultmann, "El historicismo y la naturalización de la historia," Historia y escatologia, Medrid, 1974, pp. 81-95; J. B. Cobb, "Hacia une superación del historicismo y del positiviemo," Concilium 57, 1970. p. 30ss; H. G. Gadamer, "Hermenética e historicismo," Verdad y Método, Salamanca, 1977, pp. 599-640; J. Habermas, "Positiviemo, pragmatismo, historicismo," Conocimiento e interes, Madrid, 1982, pp. 75-168; W. Pannenberg, "Del poaitiviemo al racionaliemo critico," Teorla de la ciencia y teologfa, Madrid, 1981, 37-66. 